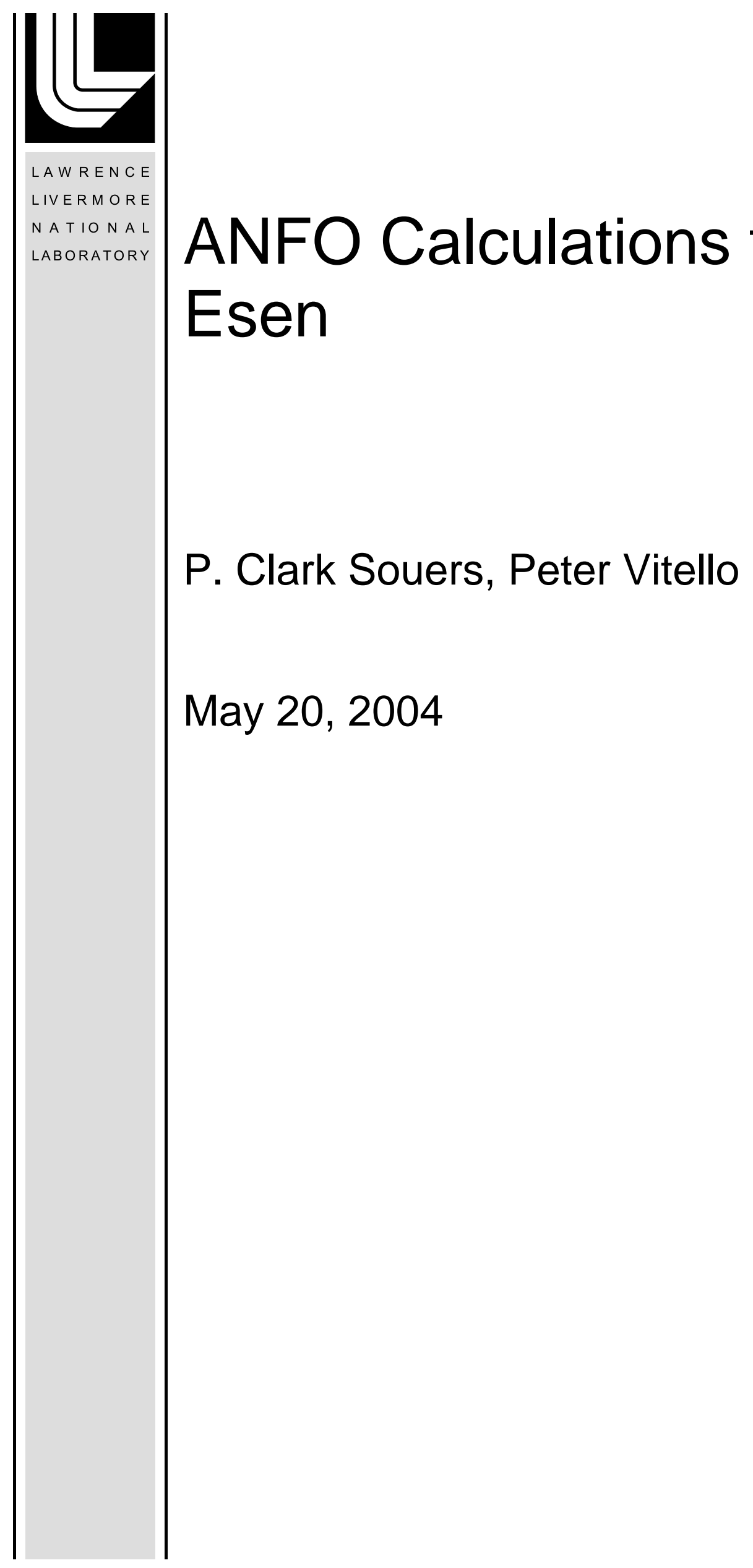

UCRL-TR-204259

ANFO Calculations for Sedat Esen

P. Clark Souers, Peter Vitello

May 20, 2004 
This document was prepared as an account of work sponsored by an agency of the United States Government. Neither the United States Government nor the University of California nor any of their employees, makes any warranty, express or implied, or assumes any legal liability or responsibility for the accuracy, completeness, or usefulness of any information, apparatus, product, or process disclosed, or represents that its use would not infringe privately owned rights. Reference herein to any specific commercial product, process, or service by trade name, trademark, manufacturer, or otherwise, does not necessarily constitute or imply its endorsement, recommendation, or favoring by the United States Government or the University of California. The views and opinions of authors expressed herein do not necessarily state or reflect those of the United States Government or the University of California, and shall not be used for advertising or product endorsement purposes.

This work was performed under the auspices of the U.S. Department of Energy by University of California, Lawrence Livermore National Laboratory under Contract W-7405-Eng-48. 


\section{ANFO Calculations for Sedat Esen}

[Note to the reviewer: Sedat is an engineer in Australia who has provided the Reference

Guide with much data. This is intended for a paper and more data for us comes because of it.]

\section{P. Clark Souers and Peter Vitello May 15, 2004}

The calculations were run with JWL++, which is a simple reactive flow model run in a finite element code. The code is a 2-dimensional CALE-type arbitrary LagrangianEulerian (ALE). This means that the problem geometry is broken into zones, each running according to Newtons' Law: force equals mass times acceleration. In the main Lagrange mode, each zone contains a fixed amount of mass. This can lead over time to tangling of zones, so a bit of Eulerian behavior is allowed in unimportant but less stable parts of the problem. This allows mass to flow between zones, thereby avoiding the tangling.

The problem is calculated in every zone and every time cycle, and the detonation progresses from the point of initation across the sample. The pressure is calculated from a linear combination of a Murnhan unreacted equation of state and a reacted explosive JWL. The rate of burn between these two species is set by a rate term with a detonation rate constant. We used the rate term

$$
\frac{d F}{d t}=G_{1} P^{b_{1}}(1-F)
$$

where $F$ is the burn fraction, $G_{1}$ the rate constant, and $b_{1}$ the power of the pressure (here set to 1). The JWL's and unreacted EOS coefficients are

\begin{tabular}{|c|c|c|}
\cline { 2 - 3 } & ANFO & P700B \\
\hline Mb's & Prill & Blend 1 \\
\hline Po & 0.80 & 1.15 \\
A & 1.5179110 & 2.844195 \\
B & 0.007146895 & 0.02754112 \\
\hline
\end{tabular}




\begin{tabular}{|c|c|c|}
$\mathbf{R}_{1}$ & 5.0 & 4.8 \\
$\mathbf{R}_{2}$ & 1.0 & 1.2 \\
$\omega$ & 0.29 & 0.31 \\
$\mathrm{E}_{\mathrm{o}}$ & 0.0350 & 0.0416 \\
$\Gamma_{\mathrm{cj}}+1$ & 3.9730740 & 4.035845 \\
$\mathrm{D}$ & 0.5050 & 0.5920 \\
\hline $\mathrm{C}_{\mathrm{o}}(\mathrm{cm} / \mu \mathrm{\mu s})$ & 0.023 & 0.067 \\
$\mathrm{~S}_{1}(\operatorname{dimlss})$ & 2.0 & 2.0 \\
$\mathrm{n}\left(\right.$ dimlss $\left.^{-1}\right)$ & 7.0 & 7.0 \\
$\mathrm{\kappa}_{\left(\mathrm{Mbar}^{-1}\right)}$ & 2463 & 194 \\
\hline
\end{tabular}

We first ran CHEETAH V3.0 for the detonation energies and $\omega$. The values of $R_{1}$ and $R_{2}$ come from a general set based on the density. This was combined with the infinite-radius detonation velocity extrapolated from the data to make a thermodynamically balanced JWL. From previous runs, we knew that ANFO's have $b_{1}=1$. We were able to estimate the rate constant $\mathrm{G}_{1}$ from the data but it is always a little different when run in the code. So we ran the smallest measured radius unconfined ratestick until we got the right detonation velocity. This occurred at $\mathrm{G}_{1}$ of $4(\mu \mathrm{s} . \mathrm{Mb})^{-1}$ for the prill and $5(\mu \mathrm{s} . \mathrm{Mb})^{-1}$ for Blend 1. Then we ran the other unconfined radii and hoped that the calculated curve matched the rest of the data. Finally, without seeing the confined data, we set up the problem with a rock liner and ran for the detonation velocity at the desired radii. No adjustment is made in going from the unconfined to the confined problem.

The code uses the $\mathrm{U}_{\mathrm{s}}-\mathrm{u}_{\mathrm{p}}$ coefficients $\mathrm{C}_{\mathrm{o}}$ and $\mathrm{S}_{1}$ for calculating the rock properties. For the unreacted explosive, we estimate $\mathrm{C}_{\mathrm{o}}$ and $\mathrm{S}_{1}$ from the densities, but they are then turned into the Murnahan coefficients using

$$
\begin{aligned}
& n=4 S_{1}-1 \\
& \kappa=\frac{1}{\rho_{0} C_{0}^{2}} .
\end{aligned}
$$

The Murnahan EOS is 


$$
\mathrm{P}_{\mathrm{k}}(\text { unreacted })=\frac{1}{\mathrm{n}_{\kappa}}\left(\frac{1}{v_{\mathrm{k}}^{\mathrm{n}}}-1\right)=\rho_{\mathrm{o}} \mathrm{U}_{\mathrm{S}}^{2}\left(1-\mathrm{v}_{\mathrm{k}}\right)
$$

and the JWL EOS is

$$
P=A \exp \left(-R_{1} v\right)+B \exp \left(-R_{2} v\right)+\frac{C}{v^{\omega+1}}
$$

The unconfined measured data used for calibration is as follows.

\begin{tabular}{ccccc} 
Prill & $\begin{array}{c}\text { diameter } \\
(\mathrm{mm})\end{array}$ & $\begin{array}{c}\text { radius } \\
(\mathrm{mm})\end{array}$ & $\begin{array}{c}1 / \mathrm{Ro} \\
(\mathrm{mm}-1)\end{array}$ & $\begin{array}{c}\text { detvel } \\
(\mathrm{mm} / \mu \mathrm{s})\end{array}$ \\
\cline { 2 - 5 } 241 & 120.5 & 0.0083 & 4.13 \\
154 & 77.0 & 0.0130 & 3.82 \\
154 & 77.0 & 0.0130 & 3.85 \\
154 & 77.0 & 0.0130 & 3.58 \\
103 & 51.5 & 0.0194 & 2.57 \\
103 & 51.5 & 0.0194 & 2.70 \\
87 & 43.5 & 0.0230 & 2.50 \\
87 & 43.5 & 0.0230 & 2.51 \\
63 & 31.5 & 0.0317 & 2.13 \\
\cline { 2 - 4 } & 28 est & & est fail
\end{tabular}

\begin{tabular}{ccccc} 
& $\begin{array}{c}\text { diameter } \\
(\mathrm{mm})\end{array}$ & $\begin{array}{c}\text { radius } \\
(\mathrm{mm})\end{array}$ & $\begin{array}{c}1 / \mathrm{Ro} \\
(\mathrm{mm}-1)\end{array}$ & $\begin{array}{c}\text { detvel } \\
(\mathrm{mm} / \mu \mathrm{s})\end{array}$ \\
\cline { 2 - 5 } Blend 1 & 236 & 118.0 & 0.0085 & 5.58 \\
& 236 & 118.0 & 0.0085 & 5.66 \\
236 & 118.0 & 0.0085 & 5.71 \\
150 & 75.0 & 0.0133 & 5.15 \\
150 & 75.0 & 0.0133 & 5.41 \\
150 & 75.0 & 0.0133 & 5.62 \\
130 & 65.0 & 0.0154 & 4.81 \\
130 & 65.0 & 0.0154 & 4.90 \\
130 & 65.0 & 0.0154 & 5.06 \\
& 101 & 50.5 & 0.0198 & 4.12 \\
82 & 41.0 & 0.0244 & 3.95 \\
82 & 41.0 & 0.0244 & 4.13
\end{tabular}




\begin{tabular}{llll}
82 & 41.0 & 0.0244 & 4.34 \\
82 & 41.0 & 0.0244 & 4.41 \\
82 & 41.0 & 0.0244 & 4.67 \\
69 & 34.5 & 0.0290 & 3.61 \\
69 & 34.5 & 0.0290 & 3.69 \\
69 & 34.5 & 0.0290 & 3.79 \\
69 & 34.5 & 0.0290 & 3.82 \\
69 & 34.5 & 0.0290 & 3.94 \\
58 & 29.0 & 0.0345 & 3.78 \\
\cline { 2 - 4 } & 20 est & \multicolumn{2}{c}{ est. fail }
\end{tabular}

One other issue needs to be described. The rock will be put into the code problem as a tube, but we need to know how thick the rock has to be. We therefore run the $30 \mathrm{~mm}$ radius ANFO prill ratestick with various thicknesses of kimberlite, and we get this picture.

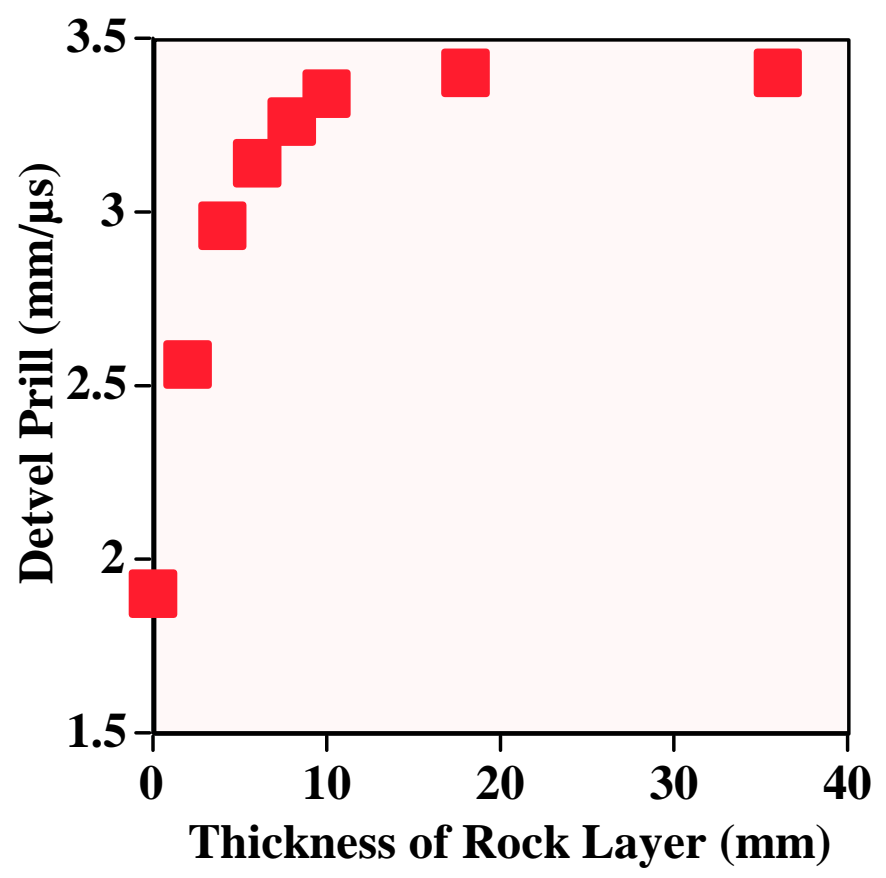

This says that $10-15 \mathrm{~mm}$ of rock is enough to get steady state detonation velocity in the problem, so we don't have to go any thicker. You may recall the paper we did, which says that we get equilibration with a small layer of confining material if the detonation velocity of the explosive is higher than the sound speed in the wall, which is the case 
here. Having a thin wall means fewer zones, which the problem is less likely to break down.

The ANFO results are shown here

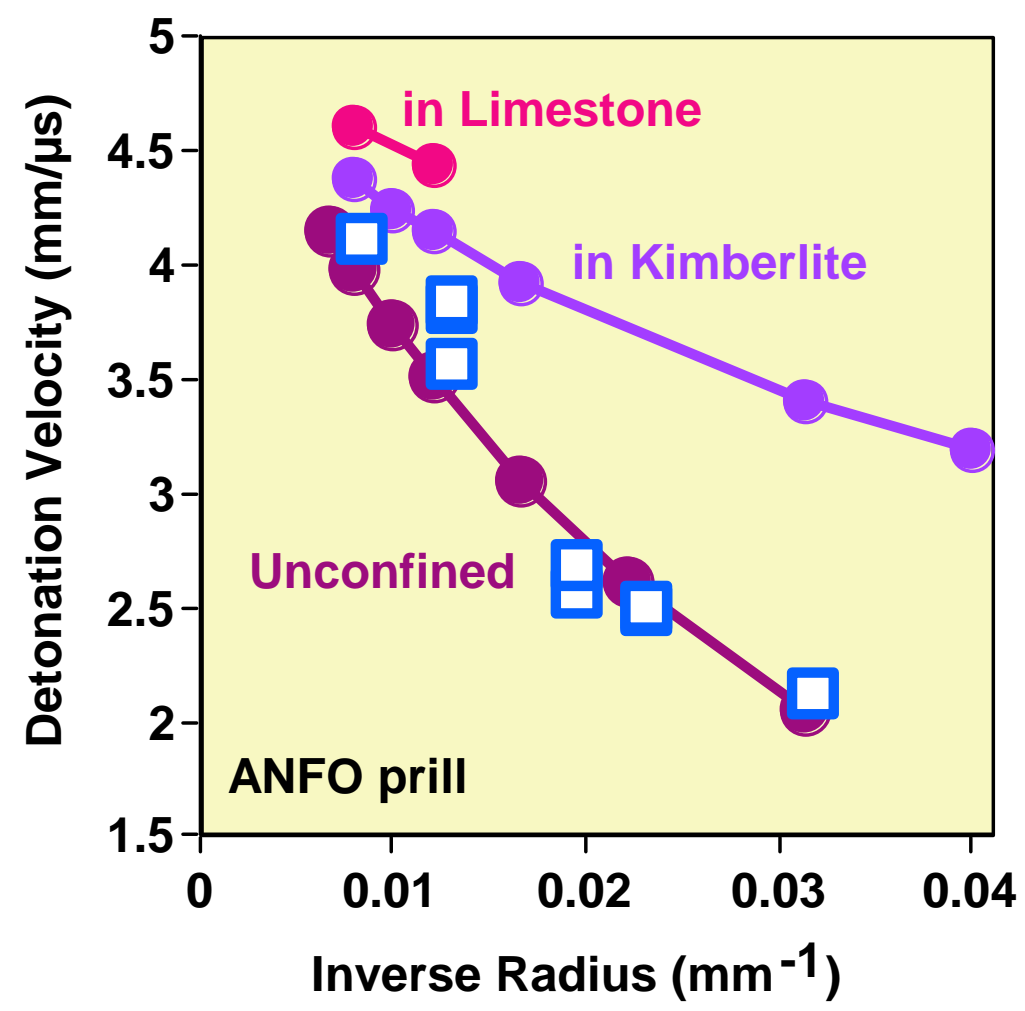

The blue squares are the unconfined data. The maroon line is the code fit, where we recall that only the last ball at the lower right is actually fit and the rest are derived. Then we calculate the increased det velocity in the two kinds of rock without changing any parameters.

Now we go to Blend 1 


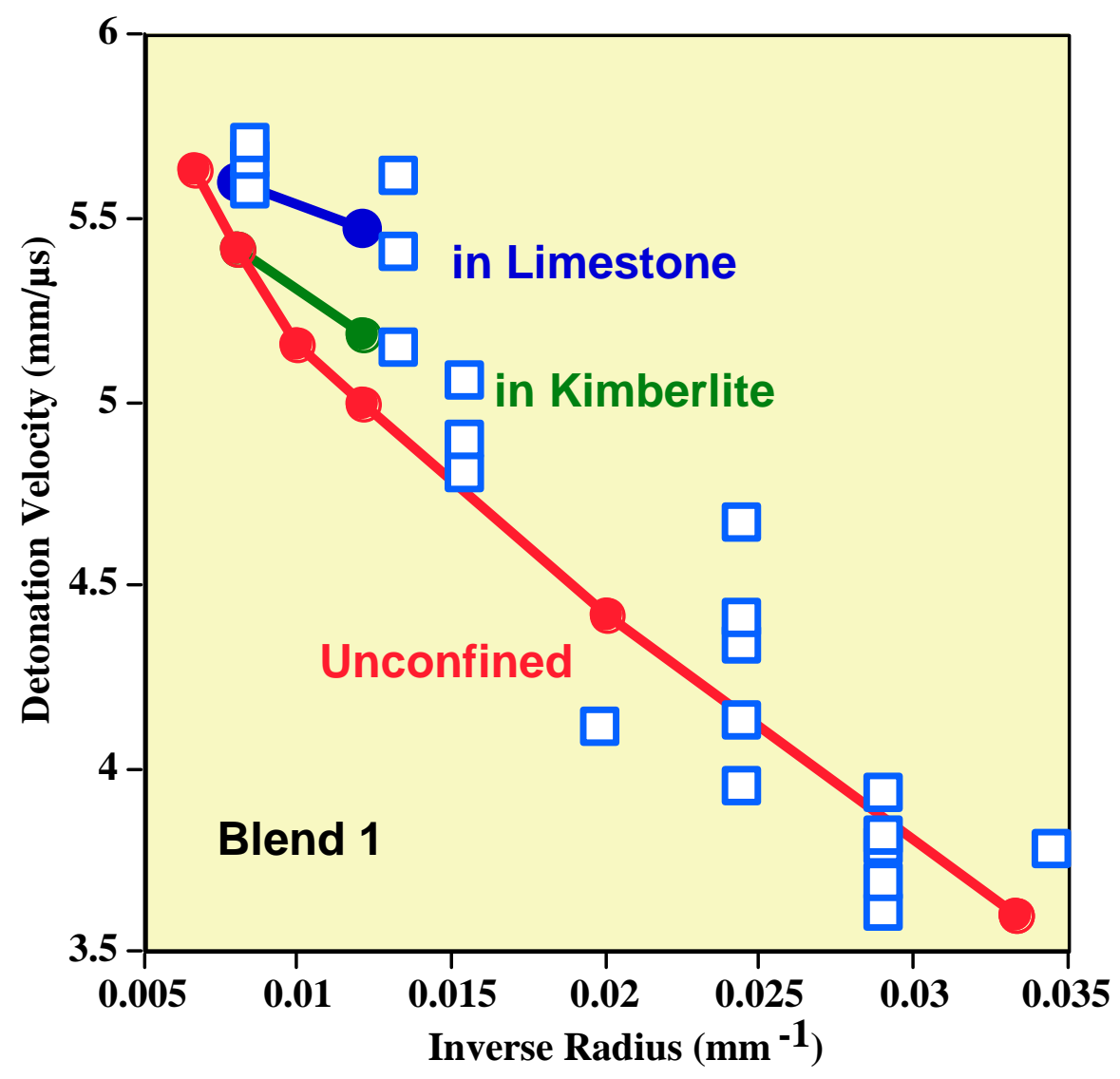

where we have the same layout.

For the purposes of your possibly wanting to replot these results, I list the numbers. ANFO Prill

\begin{tabular}{c|cccc|l} 
Dadius & \multicolumn{5}{|c}{4.87} \\
\cline { 3 - 5 }$(\mathrm{mm})$ & $\begin{array}{c}\text { Inverse } \\
(\mathrm{mm}-1)\end{array}$ & $\begin{array}{c}\text { Un- } \\
\text { confined }\end{array}$ & $\begin{array}{c}\text { Kimber- } \\
\text { lite }\end{array}$ & $\begin{array}{c}\text { Lime- } \\
\text { stone }\end{array}$ & \\
\hline 150 & 0.00667 & 4.153 & & & \\
125 & 0.00800 & 3.984 & 4.390 & 4.610 & \\
100 & 0.01000 & 3.740 & 4.254 & & \\
82.5 & 0.01212 & 3.511 & 4.150 & 4.450 & \\
60 & 0.01667 & 3.054 & 3.922 & & \\
45 & 0.02222 & 2.616 & & & \\
32 & 0.03125 & 2.059 & 3.404 & & \\
25 & 0.04000 & & 3.190 & &
\end{tabular}

Blend1

D 


\begin{tabular}{c|cccc}
$\begin{array}{c}\text { Radius } \\
(\mathrm{mm})\end{array}$ & $\begin{array}{c}\text { Inverse } \\
(\mathrm{mm}-1)\end{array}$ & $\begin{array}{c}\text { Un- } \\
\text { confined }\end{array}$ & $\begin{array}{c}\text { Kimber- } \\
\text { lite }\end{array}$ & $\begin{array}{c}\text { Lime- } \\
\text { stone }\end{array}$ \\
\hline 150 & 0.00667 & 5.635 & & \\
125 & 0.00800 & 5.423 & 5.420 & 5.600 \\
100 & 0.01000 & 5.160 & & \\
82.5 & 0.01212 & 4.993 & 5.190 & 5.470 \\
50 & 0.02000 & 4.419 & & \\
30 & 0.03333 & 3.604 & &
\end{tabular}

ANFO prill $30 \mathrm{~mm}$ unconfined with various Thicknesses of Kimberlite Thickness Detvel

\begin{tabular}{cc}
$(\mathrm{mm})$ & $(\mathrm{mm} / \mu \mathrm{s})$ \\
\hline 0 & 1.906 \\
2 & 2.567 \\
4 & 2.964 \\
6 & 3.149 \\
8 & 3.269 \\
10 & 3.340 \\
18 & 3.404 \\
36 & 3.405
\end{tabular}

\section{References}

For JWL++

P. Clark Souers, Steve Anderson, Estella McGuire and Peter Vitello, "JWL++: A Simple Reactive Flow Code Package for Detonation," Propellants, Explosives, Pyrotechnics, 25, 54-58 (2000).

Effect of wall materials on det velocity of cylinders

P. Clark Souers, Peter Vitello, Sedat Esen and H. A. Bilgin, "The Effects of Containment on Detonation Velocity," Propellants, Explosives, Pyrotechnics 29, 1926 (2004). 